\title{
Evaluation of response in malignant tumors treated with targeted agents
}

\author{
Poster No.: $\quad$ C-1134 \\ Congress: $\quad$ ECR 2015 \\ Type: $\quad$ Educational Exhibit \\ Authors: $\quad$ F. Vernuccio, D. Picone, F. Rabita, M. Amico, M. Galia, G. La \\ Tona, S. Salerno, G. Lo Re, M. Midiri; Palermo/IT \\ Keywords: $\quad$ Oncology, CT, Computer Applications-Detection, diagnosis, \\ Cancer \\ DOI: $\quad$ 10.1594/ecr2015/C-1134
}

Any information contained in this pdf file is automatically generated from digital material submitted to EPOS by third parties in the form of scientific presentations. References to any names, marks, products, or services of third parties or hypertext links to thirdparty sites or information are provided solely as a convenience to you and do not in any way constitute or imply ECR's endorsement, sponsorship or recommendation of the third party, information, product or service. ECR is not responsible for the content of these pages and does not make any representations regarding the content or accuracy of material in this file.

As per copyright regulations, any unauthorised use of the material or parts thereof as well as commercial reproduction or multiple distribution by any traditional or electronically based reproduction/publication method ist strictly prohibited.

You agree to defend, indemnify, and hold ECR harmless from and against any and all claims, damages, costs, and expenses, including attorneys' fees, arising from or related to your use of these pages.

Please note: Links to movies, ppt slideshows and any other multimedia files are not available in the pdf version of presentations.

www.myESR.org 


\section{Learning objectives}

To focus on the role of new imaging-based criteria for monitoring targeted therapies in malignant tumors in assessing treatment success, in identifying complications and in decision-making for subsequent therapy.

\section{Background}

Targeted therapies are more and more often widely used for cancer treatment. These tharapies inhibit tumor cell growth or affect tumor angiogenesis, without necessarily causing tumor cell death; hence radiological images may vary showing, for example on CT a reduced blood supply and tumor tissue necrosis as a reduced tumor density.

Tumor response assessment is essential to evaluate treatment success, to identify complications, and to lead decision-making for subsequent therapy. Many imaging techniques have been involved for evaluating tumor response to therapy, but measuring tumor shrinkage on CT is the current standard.

Traditional imaging-based approaches to assess tumor response, such as WHO criteria, were based on measuring tumor size [1], but, as already stated, target therapies may cause changes in tumour attenuation and do not necessarily cause marked tumour size reduction.

Hence, in the last decades, there has been a proliferation of many imaging-based tumorspecific response criteria whose purpose is to achieve objective assessment of treatment response in oncologic clinical trials[2-12].

\section{Findings and procedure details}

CT is the current standard in the measurement of tumor shrinkage, but other imaging modalities, such as ultrasound, MRI and PET have been involved in the newly developed response criteria to evaluate tumor response to targeted therapy.

Newly imaging based criteria include the Choi response criteria for gastrointestinal stromal tumor, modified Response Evaluation Criteria in Solid Tumors version and European Association for the Study of the Liver (EASL) criteria for hepatocellular carcinoma, Immune-related Response Criteria for melanoma and Response Assessment in Neuro-Oncology (RANO) criteria for high grade malignant glioma. PET is used 
to assess functional information and tumour viability in Cheson criteria and Positron Emission Tomography Response Criteria in Solid Tumors (PERCIST).

RECIST (Response Evaluation Criteria in Solid Tumours) were firstly published in 2000 by a task force that comprised the European Organization for Research and Treatment in Oncology, the National Cancer Institute of the United States, and the National Cancer Institute of Canada, and then revised in 2009. Main tips of RECIST 1.1 which assess response to therapy in solid tumours are reported in Table 1 [2-4].

However, due to the limits of RECIST, which are mainly based on a morphologic assessment and to the need of having functional biological information, the socalled PERCIST (PET-Response Criteria in Solid Tumors) have been proposed [5]. In PERCIST, response to therapy is evaluated as a continuous variable and expressed as a percentage change in SUL (lean body mass-normalized SUV [SUVlbm]) peak for the most active lesion at each time point between the pre- and posttreatment PET/CT studies. Though recent preclinical studies reported that PET imaging is useful tools for early response monitoring of many new target therapies, due to the limited availability of PET and to economic reasons, these criteria have not yet been further developed.

Choi criteria [6] are used to assess gastrointestinal stromal tumor response to target therapies and evaluate both size and another quantitative parameter, tumor density (see Videos 1 and 2). These criteria, incorporating tumor density and using small changes in tumor size on CT, proved to be more sensitive and more precise than RECIST in assessing the response of GISTs. The objective evaluation according to Choi Criteria is performed based on the measurements of tumor density $(\mathrm{HU})$ and size $(\mathrm{cm})$ : a combination of tumor density ( $>15 \%$ change) and modified tumor size $(>10 \%)$ proved to have an excellent prognostic value in assessing the response to imatinib in GISTs.

The therapeutic advances led to the FDA approval in 2007 of a target therapy also in patients with hepatocellular carcinoma (HCC), which is recognized as the most chemo-resistant tumour types. Nowadays, sorafenib remains the only drug that has demonstrated survival benefits in patients with advanced HCC.

According to literature, RECIST 1.1 may not be the best criteria for monitoring treatment response in HCC. For this reason, new criteria, EASL [7] and mRECIST [8] ones have been proposed to assess response to therapy in $\mathrm{HCC}$ as reported in Table 2.

Immune-related response criteria (irRC) were proposed in 2009 to evaluate response to treatment with immunotherapy in malignant melanoma[9,10] (see Table 3). 
Patients with high grade malignant glioma treated with target therapies should be evaluated at MR through RANO criteria [11] as shown in Table 4. However, an overall timepoint response is obtained combining radiological features with clinical ones.

Images for this section:

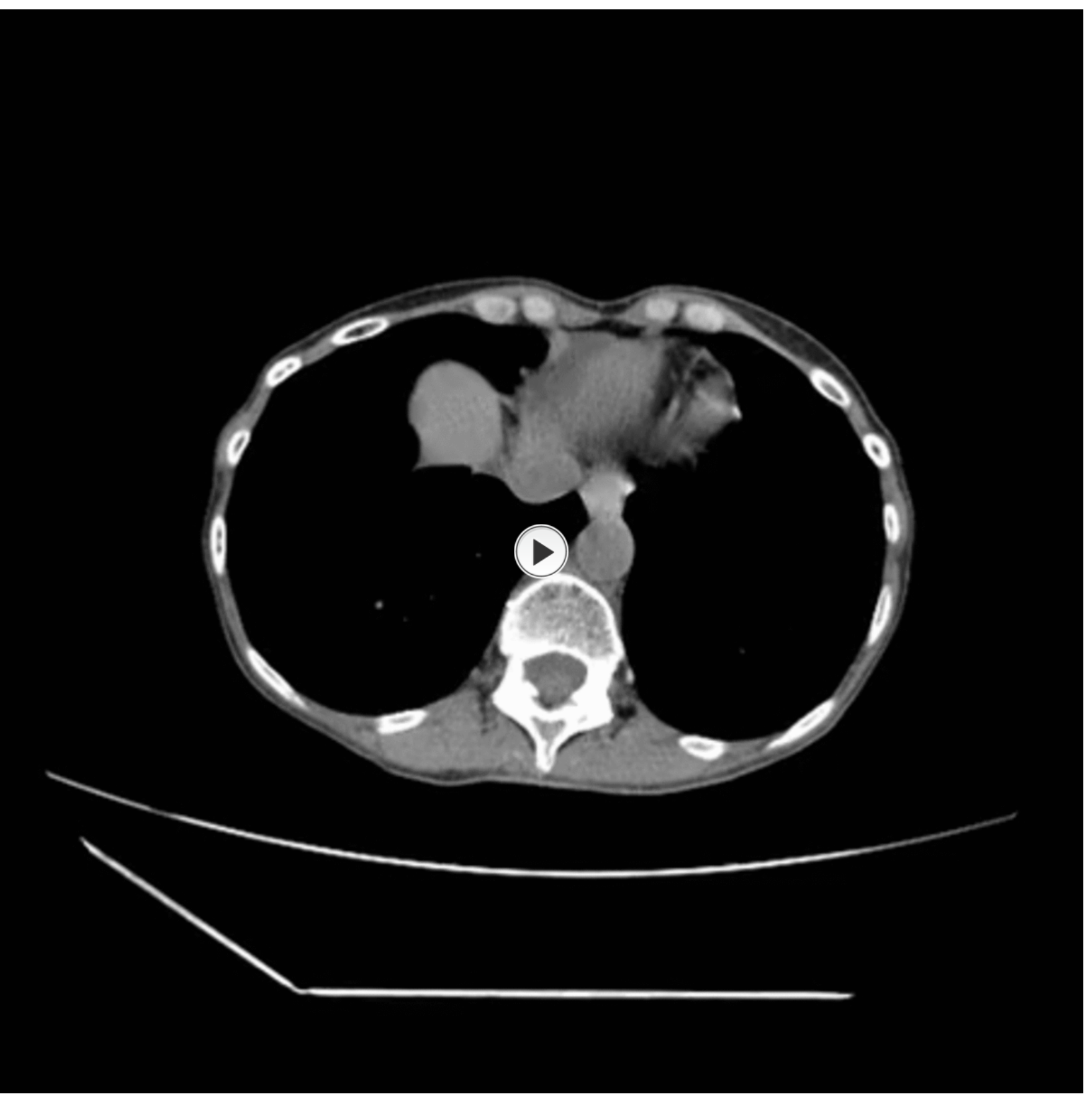

Fig. 1: Video 1. Liver metastasis from GIST. Abdominal CT shows liver increased in size, with abnormal density because of the presence in the segments $\mathrm{V}, \mathrm{VI}$ and $\mathrm{VIII}$ of a 
voluminous oval mass (diameter: $10.8 \mathrm{~cm} \times 7 \mathrm{~cm}$ ), which displaces but does not infiltrate the right hepatic vein. This mass inhomogeneously enhances, mainly in the peripheral portion, and shows a constantly hypodense area inside, as in necrosis. At least other 4 similar formations are reported, respectively, in correspondence of the segments IVa, VII - VIII , II - III and III.

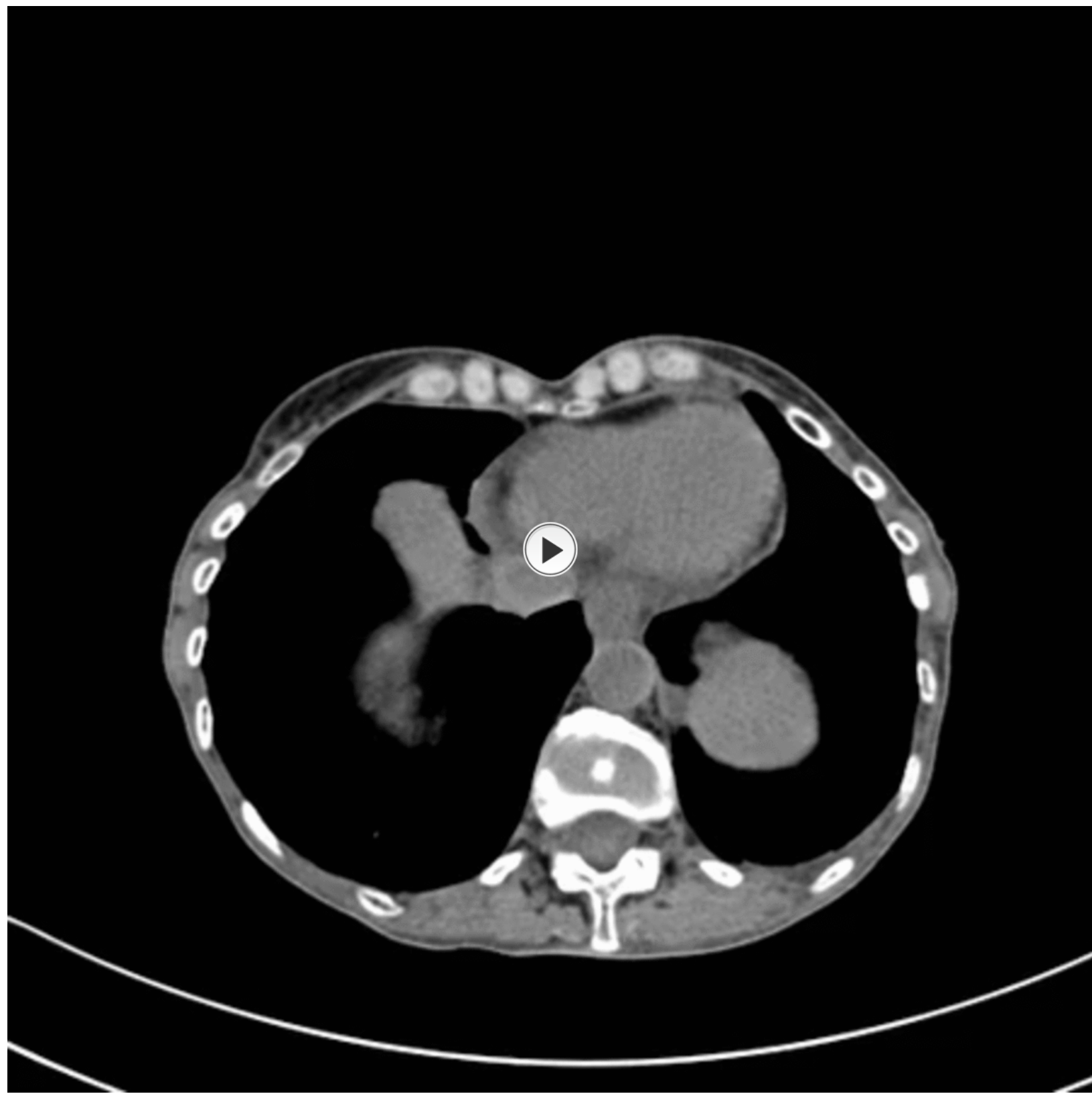

Fig. 2: Video 2. Liver metastasis from GIST after target therapy with Imatinib evaluated according to Choi Criteria in the same patient shows that the mass in the segments $\mathrm{V}$, $\mathrm{VI}$ and VIII is lower in size $(9 \mathrm{~cm} \times 6 \mathrm{~cm})$ and changed in density with more colliquative hypodense areas with more coarse calcifications inside compared to the previous control. Moreover, it is documented an increase in size of the two already known formations with a clear ring- enhancement as an expression of activity disease. 


\begin{tabular}{|l|l|l|}
\hline & mRECIST & EASL \\
\hline $\begin{array}{l}\text { Complete } \\
\text { Response }\end{array}$ & $\begin{array}{l}\text { Disappearance of any intratumoral arterial } \\
\text { enhancement in all target lesions (up to 2 } \\
\text { measurable liver lesions) }\end{array}$ & $\begin{array}{l}\text { Disappearance of any intratumoral arterial } \\
\text { enhancement in all measurable arterially- } \\
\text { enhancing liver lesions }\end{array}$ \\
\hline $\begin{array}{l}\text { Partial } \\
\text { response }\end{array}$ & $\begin{array}{l}\text { Decrease }>30 \% \text { in the sum of longest } \\
\text { diameters of "viable" target lesion }\end{array}$ & $\begin{array}{l}\text { Decrease }>50 \% \text { in the sum of the product } \\
\text { of bidimensional diameters of "viable" } \\
\text { target lesions }\end{array}$ \\
\hline $\begin{array}{l}\text { Progressive } \\
\text { disease }\end{array}$ & $\begin{array}{l}\text { Increase }>20 \% \text { in the sum of longest } \\
\text { diameters of "viable" target lesions }\end{array}$ & $\begin{array}{l}\text { Increase }>25 \% \text { in the sum of the diameters } \\
\text { of "viable" target lesions }\end{array}$ \\
\hline $\begin{array}{l}\text { Stable } \\
\text { disease }\end{array}$ & None of the above & None of the above \\
\hline
\end{tabular}

Table 2: Table 2. Assessment of response to therapy from complete response to progressive disease in advanced HCC according to mRECIST and EASL criteria.

\begin{tabular}{|c|c|}
\hline What to measure & How to assess disease progression \\
\hline $\begin{array}{l}\text { index and } \\
\text { measurable new } \\
\text { lesions are taken } \\
\text { into account }\end{array}$ & $\begin{array}{l}\text { At baseline: calculate the sum of the products of the two largest perpendicular diameters } \\
\text { (SPD) of all index lesion. } \\
\text { At follow-up, the SPD of the index lesions and of new measurable lesions are added to } \\
\text { provide the total tumor burden: } \\
\text { Tumor Burden = SPDindex lesions + SPDnew measurable lesions } \\
\text { At follow up we distinguish: } \\
\text {-Immune-related complete response: complete resolution of all measureable and non } \\
\text { measurable lesions, with no newlesions. } \\
\text {-Immune-related partial response: }>50 \% \text { decrease in the total tumor burden. } \\
\text {-Immune-related progressive disease: }>25 \% \text { increase in tumor burden. } \\
\text {-Immune-related stable disease: none of the above. } \\
\text { After at least } 4 \text { weeks the complete response, partial response or progressive disease } \\
\text { must be confirmed. }\end{array}$ \\
\hline
\end{tabular}

Table 3: Table 3. Key features of irRC showing what radiologists should assess and how to evaluate the disease after target therapies in patients with malignant melanoma.

\begin{tabular}{|c|c|c|}
\hline What to measure & How to assess disease progression & When to asses disease \\
\hline $\begin{array}{l}\text { Tumour lesions: longest } \\
\text { diameter } \geq 10 \mathrm{~mm} \text { on } \mathrm{CT} \\
\text { or } \geq 20 \mathrm{~mm} \text { on chest } \mathrm{X} \text { - } \\
\text { ray. } \\
\text { Malignant lymph nodes: } \\
15 \mathrm{~mm} \text { in short axis on } \\
\mathrm{CT} \mathrm{scan} \text {. } \\
\text { NOTE } \\
\text { Blastic bone lesions are } \\
\text { non-measurable. }\end{array}$ & $\begin{array}{l}\text { At baseline: } \leq 5 \text { lesions ( } \leq 2 \text { for each organ) are } \\
\text { considered as target lesions. } \\
\text { The sum of the longest diameters is calculated for all } \\
\text { target lesions. } \\
\text { All other non target lesions should be also recorded at } \\
\text { baseline. } \\
\text { At target lesions follow-up we distinguish: } \\
\text {-Complete Response in case of disappearance of all } \\
\text { target lesions; } \\
\text {-Partial Response when there is at least a 30\% decrease } \\
\text { in the sum of diameters of target lesions; } \\
\text { - Progressive Disease when there is at least a } 20 \% \\
\text { increase in the sum of diameters of target lesions; } \\
\text {-Stable Disease in all other conditions. }\end{array}$ & $\begin{array}{l}\text { Baseline evaluation at least } \\
4 \text { weeks before the beginning } \\
\text { of the treatment; } \\
\text { Follow-up should be based } \\
\text { on therapeutic protocol; } \\
\text { however a follow-up every } \\
6-8 \text { weeks (timed to coincide } \\
\text { with the end of a cycle) is } \\
\text { reasonable. }\end{array}$ \\
\hline
\end{tabular}

Table 1: Table 1. Key features of RECIST 1.1 showing what radiologists should assess, how and when to evaluate the disease after therapy with target therapies. 


\begin{tabular}{|c|c|}
\hline What to measure & How to assess disease progression \\
\hline $\begin{array}{l}\text { Measurable disease: bidimensionally } \\
\text { contrast enhancing lesions with } \\
\text { clearly defined margins, with two } \\
\text { perpendicular diameters of at least } \\
10 \mathrm{~mm} \text {, visible on two or more axial } \\
\text { slices that are preferably, at most, } 5 \\
\text { mm apart with } 0 \text {-mm skip } \\
\mathrm{NB} \text { : measurable lesions do not } \\
\text { include cavity, cyst, or necrosis in } \\
\text { the measurement. }\end{array}$ & $\begin{array}{l}\text { MR SEQUENCES: pre-contrast T1, T2/FLAIR and post- } \\
\text { contrast T1, with two orthogonal planes (or a volume } \\
\text { acquisition) and DWI; } \\
\text { At baseline: maximum } 5 \text { lesions considering the largest ones and } \\
\text { the most suitable for reproducible measurements. } \\
\text { At follow up measure previously defined target lesions and } \\
\text { assess non target lesions, both non enhancing ones and those } \\
\text { seen only on T2/FLAIR, and search for new lesions. }\end{array}$ \\
\hline
\end{tabular}

Table 4: Table 4. RANO criteria to evaluate at MR high grade malignant glioma treated with target therapies. 


\section{Conclusion}

Quantitative and qualitative imaging-based response criteria should be more widely known and applied in clinical practice, since traditional imaging approaches may fail in assessing response to target therapies.

\section{Personal information}

Federica Vernuccio, federicavernuccio@gmail.com

Dario Picone, dariopicone@hotmail.it

Fabrizio Rabita, fabrizio.rabita@alice.it

Giuseppe Lo Re, giuseppe.lore12@gmail.com

Section of Radiology, D.I.B.I.M.E.F.

University of Palermo

Italy

\section{References}

1. World Health Organization. WHO handbook for reporting results of cancer treatment. Geneva, Switzerland: World Health Organization, 1979.

2.Therasse $P$, Arbuck SG, Eisenhauer EA, et al. New guidelines to evaluate the response to treatment in solid tumors (RECIST Guidelines). J Natl Cancer Inst 2000;92:205-16.

3. Tirkes T, Hollar MA, Tann M, Kohli MD, Akisik F, Sandrasegaran K. Response criteria in oncologic imaging: review of traditional and new criteria. Radiographics. 2013;33:1323-41.

4. Eisenhauer EA, Therasse $P$, Bogaerts $\mathrm{J}$, et al. New response evaluation criteria in solid tumours: revised RECIST guideline (version 1.1). Eur J Cancer 2009;45:228-247.

5.Wahl RL, Jacene H, Kasamon Y, Lodge MA. From RECIST to PERCIST: Evolving Considerations for PET response criteria in solid tumors. J Nucl Med. 2009;50 Suppl 1:122S-50S. 
6. Choi $\mathrm{H}$. Response evaluation of gastrointestinal stromal tumors. Oncologist 2008;13(suppl 2):4-7.

7. Bruix J, Sherman M, Llovet JM, et al. Clinical management of hepatocellular carcinoma: conclusions of the Barcelona 2000 EASL conference. European Association for the Study of the Liver. J Hepatol 2001;35:421-430.

8. Lencioni R, Llovet JM. Modified RECIST (mRECIST) assessment for hepatocellular carcinoma. Semin Liver Dis 2010;30:52-60.

9.Wolchok JD, Hoos A, O'Day S, et al. Guidelines for the evaluation of immune therapy activity in solid tumors: immune-related response criteria. Clin Cancer Res 2009;15:7412-7420.

10. Kaufman HL, Kirkwood JM, Hodi FS, et al. The Society for Immunotherapy of Cancer consensus statement on tumour immunotherapy for the treatment of cutaneous melanoma. Nat Rev Clin Oncol 2013; 10:588.

11. Wen PY, Macdonald DR, Reardon DA, et al. Updated response assessment criteria for high-grade gliomas: response assessment in neuro-oncology working group. J Clin Oncol 2010; 28: 1963-72.

12. Cheson BD, Pfistner B, Juweid ME, et al. Revised response criteria for malignant lymphoma. J Clin Oncol 2007;25:579-586 